\title{
DENTAL EROSIVE POTENTIAL OF READY-TO-DRINK AND POWDERED SPORTS DRINKS
}

\author{
Tomasz Stefański ${ }^{1}$, Wojciech Tynior² ${ }^{2}$ Lidia Postek-Stefańska ${ }^{3}$, Anna Kloc-Ptaszna ${ }^{4}$ \\ 'Department of Orthodontics, Medical University of Silesia, Poland \\ ${ }^{2}$ Student Research Group at the Department of Pedriatric Dentistry, Medical University of Silesia, Poland \\ ${ }^{3}$ Department of Pediatric Dentistry, Medical University of Silesia, Poland \\ ${ }^{4}$ Institute of Engineering Materials and Biomaterials, Silesian University of Technology, Poland
}

\begin{abstract}
INTRODUCTION: Dental erosion is a progressive chemical degradation of tooth substance in an acidic environment, which is unrelated to the presence of dental plaque. Dehydration induced by sport activities reduces protective salivary flow and its buffering capacity, which may aggravate the erosive effect of consumed acidic beverages.

Овјестіves: To evaluate the erosive potential of ready-to-drink and powdered sports drinks.

MATERIAL AND MEthods: Seven ready-to-drink sports beverages (Oshee, Isotonic Lemon Taste, Gatorade, Powerade, Isotonic Veroni, Isostar, and 4Move) and four prepared from powder (Isoactive, Race Isotonic Drink ALE, IsoPlus, and Isostar) were analysed. A $1 \%$ citric acid was used as a reference. Human enamel specimens (five per group) were exposed to the tested solution in a short $\mathrm{pH}$-cycling model ( 1 min erosion $-5 \mathrm{~min}$ artificial saliva without mucin) repeated five times. Surface microhardness was measured before and after the $\mathrm{pH}$-cycling using a Vickers indenter. A correlation between the $\mathrm{pH}$ of the drink and enamel softening was determined.

RESULTS: All tested beverages decreased the enamel microhardness. Gatorade and Powerade had the lowest $\mathrm{pH}$ and exhibited the highest erosive potential, comparable with $1 \%$ citric acid. In general, the erosive potential of ready-to-drink beverages was higher than powdered drinks, except for Isostar. There was a significant negative correlation between enamel softening and the $\mathrm{pH}$ value of the drink $(r=-0.55)$.

ConcLusions: Sports drinks exhibit different erosive potential related to their $\mathrm{pH}$. Patients frequently consuming these beverages should be aware of the potential risk for dental erosion.
\end{abstract}

KEY WORDs: dental erosion, sports drinks, carbohydrate-electrolyte solution, oral health.

J Stoma 2019; 72, 2: 52-57

DOI: https://

\section{INTRODUCTION}

Sports drinks are noncarbonated carbohydrate-electrolyte solutions whose main purposes are to prevent dehydration (restore or maintain hydration status), to supply energy (maintain blood glucose concentration), and to replenish electrolytes lost through sweat during physical exercise [1].

Although sports drinks were originally developed for professional athletes and active amateur individuals performing intense endurance training, they are also popular within the general population, particularly adolescents and young adults $[4,10]$.

\section{JOURNAL OF} STOMATOLOGY CZASOPISMO STOMATOLOGICZNE

AdDRESS FOR CORRESPONDENCE: Tomasz Stefański, Academic Centre for Dentistry, 17 Academic Square, 41-902 Bytom, Poland, e-mail: tostef1@wp.pl

RECEIVED: 29.04.2019 • ACCEPTED: 11.06.2019 • PUBlished: 19.07.2019 
According to the European Food Safety Authority (EFSA), in order to bear the name "carbohydrate-electrolyte solution", the beverage should:

1) contain $80-350 \mathrm{kcal} / \mathrm{l}$ from carbohydrates, and more than $75 \%$ of the energy should be derived from carbohydrates that induce a high glycaemic response, such as glucose, glucose polymers (e.g. maltodextrin), and sucrose;

2) contain between $20 \mathrm{mmol} / \mathrm{l}(460 \mathrm{mg} / \mathrm{l})$ and $50 \mathrm{mmol} / \mathrm{l}$ $(1150 \mathrm{mg} / \mathrm{l})$ of sodium;

3) have an osmolality between 200 and $330 \mathrm{mOsm} / \mathrm{kg}$ water [7].

Beverages with an osmolality $300 \pm 10 \% \mathrm{mOsm} / \mathrm{kg}$ water may be named "isotonic" because their concentration of osmotic active substances per unit of mass is the same as in human plasma. Isotonic or slightly hypotonic solutions are thought to enhance water absorption during exercise $[7,19]$.

To supress the salty taste of the sport drinks and improve their palatability, citric acid is usually added [6]. The acidulant ingredients play a significant role in the pathogenesis of dental erosion by lowering the $\mathrm{pH}$ of the solution and reducing its degree of saturation with respect to dental (enamel) hydroxyapatite. Chemical properties, such as $\mathrm{pH}$ value, and calcium and phosphate concentrations, are important in determining the erosive potential $[2,3,22,24]$. However, on the food package labels such information is usually missing [13].

Sports drinks may be consumed before, during, and after exercise. It is important to note that dehydration induced by strenuous physical activity reduces protective salivary flow and its buffering capacity and may aggravate the erosive effect of the consumed acidic carbohydrate-electrolyte beverage [6]. This factor predisposes athletes to be at a higher risk of developing dental erosion [11]. Due to their high sugar content, sports drinks have cariogenic potential by increasing metabolic activity of Streptococcus mutans [26]. However, controversy exists regarding the direct relationship between use of sports drinks and erosive toothwear in cross-sectional observational studies $[1,12,15,18,21]$.

\section{OBJECTIVES}

The aim of this experiment was to determine the erosive potential of commercially available sports drinks in two forms: ready-to-drink and prepared from powder.

\section{MATERIAL AND METHODS}

\section{BEVERAGE SELECTION AND PREPARATION}

Seven ready-to-drink (Oshee, Isotonic Lemon Taste, Gatorade, Powerade, Isotonic Veroni, Isostar, and 4Move) and four powdered sports drink (Isoactive, Race Isotonic Drink ALE, IsoPlus, and Isostar) were purchased.
Data on the composition of the selected products were taken from the food label and shown in Tables 1 and 2 . The powdered sports drinks were prepared according to the manufacturers' instructions using a precision laboratory scale and distilled deionised water as a solvent. The $\mathrm{pH}$ value of the tested beverages was analysed using a standard $\mathrm{pH}$ meter (Five Easy, Mettler Toledo) with a glass electrode (LE409, Mettler Toledo), calibrated with reference buffers of $\mathrm{pH} 4.00$ and $\mathrm{pH} 7.00$, at $21^{\circ} \mathrm{C}$. Before measurement, the solutions were mixed thoroughly with a magnetic stirrer. A reference erosive solution was $1 \%$ w/v citric acid (Sigma-Aldrich Co., St. Louis, Mo., USA) with $\mathrm{pH}$ adjusted to 3.80 with sodium hydroxide.

\section{SPECIMEN PREPARATION}

Enamel specimens were prepared from freshly extracted, non-damaged, and caries-free human permanent premolar and molar teeth extracted for orthodontic reasons after patient verbal consent. Enamel slabs were cut from buccal surfaces of the teeth using a lowspeed, water-cooled diamond saw (Minitom, Struers, Copenhagen, Denmark). Each specimen was prepared from one tooth. The specimens were embedded in acrylic resin (DuroFast, Struers) in a hot mounting press machine (CitoPress-20, Struers). Afterwards, the enamels were subjected to wet-grinding with abrasive paper (500-2000 grit, Waterproof Silicon Carbide Grinding Paper, Struers, Erkrath, Germany) and polishing with felt paper wet by diamond suspension ( $1 \mu \mathrm{m}$ Diamond Paste, Struers). This procedure was performed with a semiautomatic grinding/polishing device (Tegramin-30, Struers). Removal of the outermost enamel was controlled with micrometer and a layer of up to $200 \mu \mathrm{m}$ was lost. Finally, the specimens were ultrasonically cleaned for 15 min with distilled water to remove the smear layer. Specimens with visible surface defects were discarded. Acceptable specimens having a mean Vickers Hardness Number (VHN) above 380 were selected. The exposed area of enamel was approximately $2-3 \mathrm{~mm}^{2}$. Prior to use, the prepared enamel slabs were stored in a saturated mineral solution (1.5 mM CaCl$, 0.9 \mathrm{mM} \mathrm{KH}_{2} \mathrm{PO}_{4}, 150 \mathrm{mM}$ $\mathrm{KCl}, 1 \mathrm{mM} \mathrm{NaN}, 20 \mathrm{mM}$ TRIS, $\mathrm{pH}$ 7.0) in refrigerator at $4^{\circ} \mathrm{C}$.

\section{EXPERIMENTAL DESIGN}

Sixty enamel specimens were randomly allocated to one of 12 groups $(n=5)$ to receive different sports drinks or reference solution. After initial immersion in artificial saliva for $10 \mathrm{~min}$, specimens were subjected to $\mathrm{pH}$-cycling. One cycle consisted of a 1-min exposition to the tested beverage or citric acid solution $(10 \mathrm{ml} / \mathrm{speci}$ men, $21^{\circ} \mathrm{C}$ with slow stirring) and 10 -min immersion in artificial saliva, which served as a remineralising medium (10 $\mathrm{ml} /$ specimen, at $36^{\circ} \mathrm{C}$ without stirring). The artifi- 


\begin{tabular}{|c|c|c|c|c|c|c|c|}
\hline 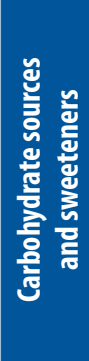 & 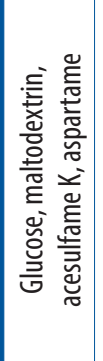 & 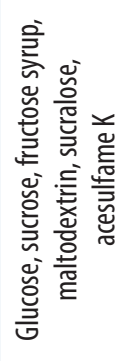 & 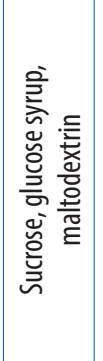 & 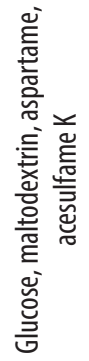 & 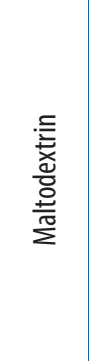 & 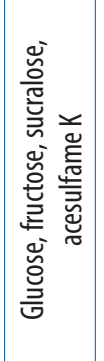 & 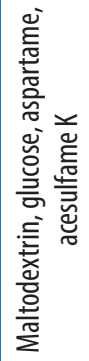 \\
\hline 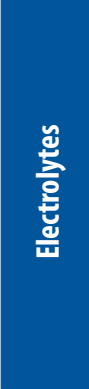 & 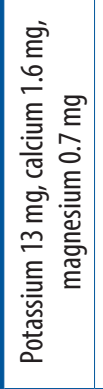 & 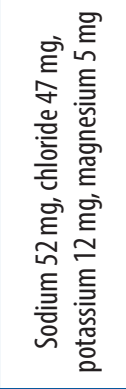 & 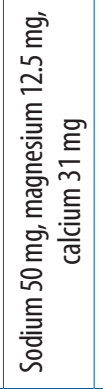 & $\simeq$ & $\cong$ & 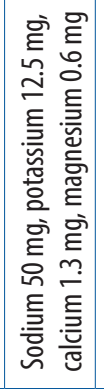 & $\check{\Xi}$ \\
\hline 늠 & $\stackrel{m}{\circ}$ & $\stackrel{m}{0}$ & $\stackrel{m}{0}$ & $\stackrel{m}{0}$ & $\stackrel{?}{0}$ & $\stackrel{m}{0}$ & $\stackrel{2}{0}$ \\
\hline 논 & 0 & 0 & 0 & $\stackrel{\sim}{\tilde{a}}$ & 0 & 0 & 0 \\
\hline $\begin{array}{l}\text { 등 } \\
\text { 홍 } \\
\end{array}$ & $\hat{\tilde{a}} \dot{v}$ & 0 & 0 & 喿 & 0 & 0 & 0 \\
\hline $\begin{array}{l}\text { 홓응 } \\
\text { 흥응 } \\
\text { 홍 }\end{array}$ & : & ஸे & శి & Li & $\tilde{n}$ & $\stackrel{\circ}{\text { mे }}$ & o. \\
\hline 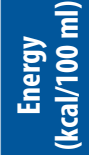 & $\nsim$ & \pm & \pm & $\approx$ & \pm & $\circ$ & $\nsim$ \\
\hline 言 & 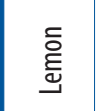 & 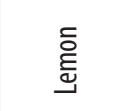 & 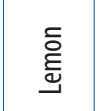 & 离 & 鸹 & $\stackrel{\overline{0}}{\stackrel{\bar{E}}{\Psi}}$ & 岛 \\
\hline 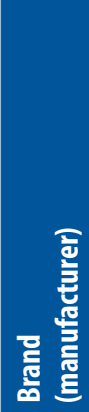 & 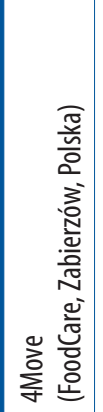 & 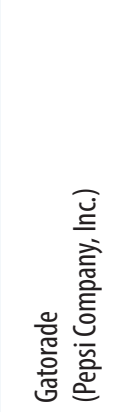 & 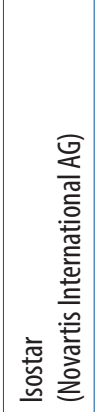 & 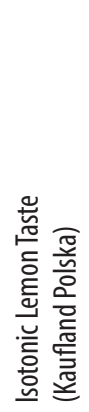 & 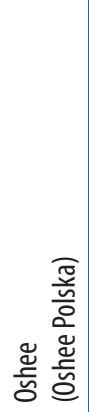 & 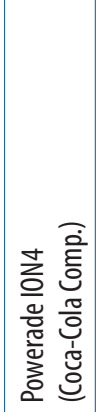 & 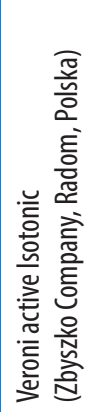 \\
\hline
\end{tabular}

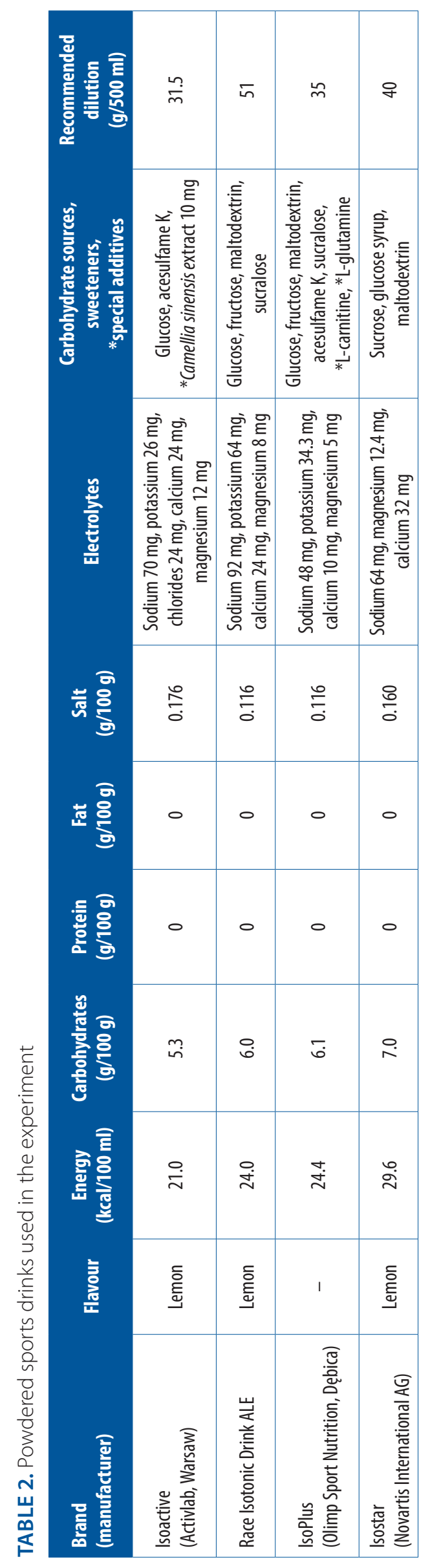


cial saliva was mixed according to the following formulation: $2700 \mathrm{mg} / \mathrm{l}$ porcine gastric mucin, $1270 \mathrm{mg} / \mathrm{l} \mathrm{KCl}$, $580 \mathrm{mg} / \mathrm{ml} \mathrm{NaCl}, 340 \mathrm{mg} / \mathrm{l} \mathrm{Na}{ }_{2} \mathrm{HPO}_{4}, 330 \mathrm{mg} / \mathrm{K} \mathrm{KH}_{2} \mathrm{PO}_{4}$, $200 \mathrm{mg} / \mathrm{l}$ urea, $170 \mathrm{mg} / \mathrm{l} \mathrm{CaCl}_{2} \times 2 \mathrm{H}_{2} \mathrm{O}, 160 \mathrm{mg} / \mathrm{l} \mathrm{NaSCN}$, $160 \mathrm{mg} / \mathrm{dm}^{3} \mathrm{NH}_{4} \mathrm{Cl}, 30 \mathrm{mg} / \mathrm{l}$ glucose, and $2 \mathrm{mg} / \mathrm{l}$ ascorbic acid, $\mathrm{pH}$ adjusted to 6.4. Freshly opened or prepared drinks were used at room temperature $\left(23^{\circ} \mathrm{C}\right)$. Before changing solutions, the specimens were immersed in deionised water $(100 \mathrm{ml})$ and gently dried with an air spray.

\section{SURFACE MICROHARDNESS MEASUREMENT}

Specimen surface microhardness (SMH) was determined at baseline (SMH 0) and after exposition to sports drinks (SMH 1) by one operator blinded to the group assignment. The indentations were made by Vickers diamond with 100-g load and dwell time of 15 s using a computer-aided FM-700 microhardness tester coupled to FM-ARS software (Future Tech Corp., Tokyo, Japan). Five indentations at an interval of $100 \mu \mathrm{m}$ were made for each specimen, and the mean SMH was calculated. The percentage SMH change (\%SMHC) was determined as follows: $\% \mathrm{SMHC}=\left[\left(\mathrm{SMH}_{1}-\mathrm{SMH}_{0}\right) / \mathrm{SMH}_{0}\right] \times 100[23]$.

\section{STATISTICAL ANALYSIS}

Shapiro-Wilk test was used to test normal distribution of the data and Levene test to verify homogeneity of variance. One-way ANOVA and Tukey's post hoc tests were performed to check statistically significant differences in \%SMHC. The level of significance was set at $p=0.05$. Statistical analyses were carried out using Excel 2007 (Microsoft) and Statistica software (StatSoft, ver. 10.0). The correlation between the $\mathrm{pH}$ of the drink and enamel softening was calculated.

\section{RESULTS}

Table 3 summarises the results of the acidity and mean percentage surface microhardness change (\%SMHC) after exposition to the studied beverages. All the examined solutions caused a significant surface softening $(p<0.0001)$. Powerade and Gatorade had the lowest $\mathrm{pH}$ and induced the greatest enamel softening, which was comparable to the reference citric acid solution. The other beverages resulted in significantly lower enamel softening $(p<0.05)$. In a comparison of the ready-to-drink beverages with the drinks prepared from powder, the latter showed significantly lower \%SMHC $(p<0.05)$. A negative linear correlation $(r=-0.55, p<0.05)$ was observed between the $\mathrm{pH}$ value and enamel softening (\%SMHC).

\section{DISCUSSION}

The present study demonstrated that sports drinks are capable of eroding enamel to different extents, but to a lesser degree than pure $1 \%$ citric acid. The erosive potential of the sports drinks could be ascribed to the presence of citric and ascorbic acid in their basic formulations. Chemical dissolution of dental tissue may be caused by $\mathrm{H}^{+}$ions and anions capable of binding or complexing calcium.

The highest erosive potential of the Gatorade and Powerade could be explained by their relatively low $\mathrm{pH}$ and low calcium content. This observation concurs

TABLE 3. Acidity of the studied beverages, mean ( \pm standard deviation) baseline enamel microhardness $\left(S M H_{0}\right)$, microhardness after short-term erosion-remineralisation cycle $\left(\mathrm{SMH}_{1}\right)$, and calculated percentage surface microhardness change (\%SMHC)

\begin{tabular}{|l|c|c|c|c|c|c|}
\hline \multirow{2}{*}{ Group } & \multicolumn{2}{c}{$\mathbf{p H}$} & $\begin{array}{c}\text { Physical state at } \\
\text { purchase }\end{array}$ & \multicolumn{2}{c}{ SMH $_{0}$} & \multicolumn{2}{c|}{ SMH $_{1}$} & \multicolumn{2}{c|}{ \%SMHC } \\
\hline Oshee & 3.87 & Liquid & $443.04 \pm 10.28$ & $399.20 \pm 11.72$ & $-43.84 \pm 12.53 \%$ & B \\
\hline Isotonic Lemon Taste & 3.92 & Liquid & $437.04 \pm 9.09$ & $400.25 \pm 13.96$ & $-36.80 \pm 17.63 \%$ & B \\
\hline Gatorade & 3.25 & Liquid & $431.73 \pm 10.21$ & $367.49 \pm 12.95$ & $-64.25 \pm 8.02 \%$ & A \\
\hline Powerade & 2.66 & Liquid & $430.76 \pm 15.52$ & $362.36 \pm 14.34$ & $-68.40 \pm 12.17 \%$ & A \\
\hline Isotonic Veroni & 3.98 & Liquid & $430.90 \pm 11.09$ & $401.63 \pm 10.33$ & $-29.27 \pm 9.24 \%$ & B \\
\hline Isostar & 4.02 & Liquid & $431.02 \pm 14.55$ & $398.30 \pm 19.54$ & $-32.72 \pm 9.97 \%$ & B \\
\hline 4Move & 3.57 & Liquid & $440.33 \pm 17.60$ & $391.50 \pm 15.28$ & $-48.83 \pm 9.98 \%$ & B \\
\hline Isoactive & 3.82 & Powder & $430.52 \pm 13.36$ & $407.82 \pm 11.98$ & $-22.70 \pm 7.86 \%$ & B \\
\hline Race Isotonic Drink ALE & 4.43 & Powder & $437.00 \pm 14.98$ & $409.75 \pm 15.81$ & $-27.25 \pm 6.78 \%$ & B \\
\hline IsoPlus & 3.42 & Powder & $452.44 \pm 14.82$ & $418.39 \pm 19.25$ & $-34.05 \pm 7.23 \%$ & B \\
\hline Isostar & 3.88 & Powder & $439.56 \pm 17.18$ & $418.12 \pm 13.53$ & $-21.44 \pm 7.66 \%$ & B \\
\hline 1\% citric acid & 3.80 & - & $435.04 \pm 14.93$ & $364.55 \pm 17.90$ & $-70.49 \pm 9.54 \%$ & A \\
\hline
\end{tabular}

Values with different letters are significantly different from each other. 
with those drawn from other in vitro studies $[8,9,11$, $18,20]$. Of the three most popular sports drinks worldwide (Gatorade, Powerade, and Isostar), the erosive potential of Isostar is significantly lower, which can be explained by its high calcium concentration of $8.20 \mathrm{mmol} / \mathrm{l}$ (the calcium concentrations of Gatorade and Powerade are $0.13 \mathrm{mmol} / \mathrm{l}$ and $0.25 \mathrm{mmol} / \mathrm{l}$, respectively) [11].

It should be noted that the presence of remineralisation medium in the study protocol may not reflect reduced salivary flow during long physical exercise, and in such instances the microhardness loss would be even higher.

The degree of saturation with respect to hydroxyapatite $\left(\mathrm{DS}_{\mathrm{HAP}}\right)$ is an important parameter related to the rate of erosion $[2,3,22,24]$. DS depends on the calcium, phosphate, and fluoride concentration and $\mathrm{pH}$ of the solution. The concentration gradient of those ions constitutes a thermodynamic driving force for dissolution. In theory, saturated or supersaturated solution $\left(\mathrm{DS}_{\mathrm{HAP}} \geq 1.0\right)$ is not expected to induce enamel dissolution. It was found that a threshold condition for citric acid with a $\mathrm{pH}$ of 3.3 is defined by a calcium concentration of $120 \mathrm{mM}$ and phosphate concentration of $0.57 \mathrm{mM}$ [7]. Although highly undersaturated (DS ${ }_{\mathrm{HAP}}$ $\sim 0.104$ ), this solution does not exhibit significant erosive potential to the enamel. Considering these observations, sports drinks with lower acidity and higher calcium and phosphate content may be safer for teeth [24], and the present study and the others discussed below support this notion.

The powdered sports drink formulas used in the study contained variable amounts of calcium: IsoPlus $2.5 \mathrm{mmol} / \mathrm{l}$, Race Isotonic Drink ALE and Isoactive $6 \mathrm{mmol} / \mathrm{l}$, and Isostar $8 \mathrm{mmol} / \mathrm{l}$. Generally, the calcium content in ready-to-drink formulas is lower, except for Isostar. Sports drinks prepared from powder had lower erosive potential than that of Gatorade and Powerade. Among sports drinks from the Australian market, two with the highest calcium concentration have been shown to have the lowest erosive potential (Endura with $3 \mathrm{mM}$ calcium as calcium amino acid chelate, and Sukkie with $11 \mathrm{mM}$ calcium as calcium lactate). However, due to their relatively high $\mathrm{pH}$, the taste of those drinks was less acceptable than that of more acidic sports beverages [5]. In an in situ study, an experimental carbohydrate-electrolyte sports orange drink with $8.75 \mathrm{mM}$ calcium ingested during exercise had significantly lower erosive potential [25]. The other method that successfully minimised the erosion effect of sports drinks was substituting citric acid with malic acid and increasing the $\mathrm{pH}[14]$.

There are conflicting findings on the relationship between the use of sports drinks and erosive toothwear in several cross-sectional observational studies. While some studies have reported a causal relationship [18], others found no significant association between dental erosion and consumption of sports drinks $[1,12,15,21]$. Bearing in mind the multifactorial aetiology of dental erosion, focusing on a single type of drink may be too simplistic [6]. Moreover, the results of the present study highlight the differences of the erosive potential among different brands of sports drinks and their formulations. This fact should be taken into account in conducting further cross-sectional studies.

\section{CONCLUSIONS}

Sports drinks exhibit different erosive potential related to their $\mathrm{pH}$. Patients frequently consuming these beverages should be aware of the potential risk for dental erosion.

\section{CONFLICT OF INTEREST}

The authors declare no potential conflicts of interest with respect to the research, authorship, and/or publication of this article.

\section{References}

1. Antunes LS, Veiga L, Nery VS, Nery CC, Antunes LA. Sports drink consumption and dental erosion among amateur runners. J Oral Sci 2017; 59: 639-643.

2. Barbour ME, Parker DM, Allen GC, Jandt KD. Enamel dissolution in citric acid as a function of calcium and phosphate concentrations and degree of saturation with respect to hydroxyapatite. Eur J Oral Sci 2003; 111: 428-433.

3. Barbour ME, Parker DM, Allen GC, Jandt KD. Human enamel erosion in constant composition citric acid solutions as a function of degree of saturation with respect to hydroxyapatite. J Oral Rehabil 2005; 32: 16-21.

4. Broughton D, Fairchild RM, Morgan MZ. A survey of sports drinks consumption among adolescents. Br Dent J 2016; 220: 639-643.

5. Cochrane NJ, Yuan Y, Walker GD, Shen P, Chang C, Reynolds C. Erosive potential of sports beverages. Aust Dent J 2012; 57: 359-364.

6. Coombes JS. Sports drinks and dental erosion. Am J Dent 2005; 18: 101-104

7. European Food Safety Authority (EFSA). Scientific opinion on the substantiation of health claims related to carbohydrate-electrolyte solutions and reduction in rated perceived exertion/effort during exercise (ID 460,466, 467, 468), enhancement of water absorption during exercise (ID 314, 315, 316, 317, 319, 322, 325, 332 , $408,465,473,1168,1574,1593,1618,4302,4309)$, and maintenance of endurance performance (ID 466, 469) pursuant to Article 13(1) of Regulation (EC) No 1924/2006 European Food Safety Authority. EFSA Journal 2011; 9(6): 2211.

8. Hooper SM, Hughes JA, Newcombe RG, Addy M, West NX. A methodology for testing the erosive potential of sports drinks. J Dent 2005; 33: 343-348.

9. Kitchens M, Owens BM. Effect of carbonated beverages, coffee, sports and high drinks, and bottled water on the in vitro erosion characteristics of dental enamel. J Clin Pediatr Dent 2007; 31: 153-159.

10. Larson N, DeWolfe J, Story M, Naumark-Sztainer D. Adolescent consumption of sports and energy drinks: linkages to higher physical activity, unhealthy beverage patterns, cigarette smoking and screen media use. J Nutr Educ Behav 2014; 46: 181-187. 
11. Lussi A, Megert B, Shellis RP, Wang X. Analysis of the erosive effect of different dietary substances and medications. Br J Nutr 2012; 107: 252-262.

12. Mathew T, Casamassimo PS, Hayes JR. Relationship between sports drinks and dental erosion in 304 University Athletes in Columbus, Ohio, USA. Caries Res 2002; 36: 281-287.

13. Mettler S, Rusch C, Colombani PC. Osmolality and $\mathrm{pH}$ of sport and other drinks available in Switzerland. Schweiz Z Med Traumatol 2006; 54: 92-95.

14. Meurman JH, Harkonen M, Naveri H, Koskinen J, Torkko H, Rytomaa I. Experimental sports drinks with minimal dental erosion effect. Scand J Dent Res 1990; 98: 120-128.

15. Milosevic A, Kelly MJ, McLean AN. Sports suplement drinks and dental health in competitive swimmers and cyclists. Br Dent J 1997; 182: 303-308.

16. Milosevic A. Sports drinks hazard to teeth. Br J Sports Med 1997; 31: 28-30.

17. Ostrowska A, Piątowska D. The effect of sports isotonic drinks on the prevalence of erosive lesions in teeth of athletes. Dent Forum 2011; 1: 35-40 [In Polish].

18. Ostrowska A, Szymański W, Kołodziejczyk Ł, Bołtacz-Rzepkowska E. Evaluation of the erosive potential of selected isotonic drinks: in vitro studies. Adv Clin Exp Med 2016; 25: 1313-1319.

19. Rodriguez NR, DiMarco NM, Langley S. Position of the American Dietetic Association, Dietitians of Canada, and the American College of Sports Medicine: nutrition and athletic performance. J Am Diet Assoc 2009; 109: 509-527.

20. Sampaio MA, Passos VF, Lima JPM, Santiago SL, Rodrigues LKA Carbohydrate-electrolyte drinks exhibit risks for human enamel surface loss. Restor Dent Endod 2016; 41: 246-254.

21. Sirimaharaj V, Brearley Messer L, Morgan MV. Acidic diet and dental erosion among athletes. Aust Dent J 2002; 47: 228-236.

22. Stefański T, Malara P, Kloc-Ptaszna A, Janoszka B, Postek-Stefańska L, Tyrpień-Golder, Dobrzański LA. Erosive potential of calcium-supplemented citric acid on bovine enamel. Arch Mat Sci Eng 2013; 64: 175-181.

23. Stefański T, Malara P, Kloc-Ptaszna, Postek-Stefańska L. A review of methods for evaluating dental erosive lesions. Dent Forum 2015; 2: 75-84 [In Polish].

24. Stefański T, Postek-Stefańska L. Possible ways of reducing dental erosive potential of acidic beverages. Aust Dent J 2014; 59: 280-288.

25. Venables MC, Shaw L, Jeukendrup AE, Roedig-Penman A, Finke M, Newcombe RG, Parry J, Smith AJ. Erosive effect of a new sports drink on dental enamel during exercise. Med Sci Sports Exerc 2005; 37: $39-44$

26. Vinson LA, Goodlett AK, Huang R, Eckert GJ, Gregory RL. In vitro effects of sports and energy drinks on Streptococcus mutans biofilm formation and metabolic activity. J Dent Child (Chic) 2017; 84: 108-114. 